\title{
Heat shock proteins and hypometabolism: adaptive strategy for proteome preservation
}

This article was published in the following Dove Press journal:

Research and Reports in Biology

29 March 20II

Number of times this article has been viewed

\section{Kenneth B Storey \\ Janet M Storey}

Departments of Biology and Chemistry, Carleton University,

Ottawa, ON, Canada
Correspondence: Kenneth Storey Departments of Biology and Chemistry, Carleton University, II 25 Colonel By Drive, Ottawa,

ON, Canada KIS 5B6

$\mathrm{Tel}+\mathrm{I} 6135203678$

$\mathrm{Fax}+\mathrm{I} 6135203749$

Email kenneth_storey@carleton.ca
Abstract: To survive under harsh environmental conditions many organisms retreat into hypometabolic states where metabolic rate may be reduced by $80 \%$ or more and energy use is reprioritized to emphasize key functions that sustain viability and provide cytoprotection. ATP-expensive activities, such as gene expression, protein turnover (synthesis and degradation), and the cell cycle, are largely shut down. As a consequence, mechanisms that stabilize the existing cellular proteome can become critical for long-term survival. Heat shock proteins (HSPs) are well-known for their actions as chaperones that act to fold new proteins or refold proteins that are damaged. Indeed, they are part of the "minimal stress proteome" that appears to be a ubiquitous response by all cells as they attempt, successfully or unsuccessfully, to deal with stress. The present review summarizes evidence that HSPs are also a conserved feature of natural animal hypometabolism including the phenomena of estivation, hibernation, diapause, cold-hardiness, anaerobiosis, and anhydrobiosis. That is, organisms that retreat into dormant or torpid states in anticipation that environmental conditions may become too difficult for normal life also integrate the use of HSPs to protect their proteome while hypometabolic. Multiple studies show a common upregulation of expression of $h s p$ genes and/or HSP proteins prior to or during hypometabolism in organisms as diverse as ground squirrels, turtles, land snails, insects, and brine shrimp and in situations of both preprogrammed dormancies (eg, seasonal or life stage specific) and opportunistic hypometabolism (eg, triggered by desiccation or lack of oxygen). Hence, HSPs are not just a "shock" response that attempts to rescue cells from damaging stress but are a key protective strategy that is an integral component of natural states of torpor and dormancy.

Keywords: chaperone proteins, metabolic rate depression, estivation, anaerobiosis, hibernation, diapause, cold-hardiness

\section{Introduction}

Throughout their lives, all organisms must deal with changes in environmental and physiological parameters and are almost constantly adjusting their metabolism, aiming to maintain homeostasis but sometimes requiring extreme responses in a bid to remain viable. Environmental challenges can include changes in oxygen, nutrient and water availability, salinity, temperature, atmospheric pressure, toxic metals, and UV radiation, to name a few. All organisms have inherent flexibility to deal with minor stresses on their metabolism and many have well-developed biochemical adaptations that are used to deal with extreme stresses that are part of their natural experience. ${ }^{1}$ For example, the human experience of low oxygen stress is that as little as 4 minutes without oxygen can cause brain damage whereas painted turtles, the champions of vertebrate anaerobiosis, 
have adaptations that allow them to hibernate underwater without oxygen for 3 months or more. , $^{2,3}$

Although not part of the human experience, the key to survival of extreme environmental stress for many species is to temporarily abandon normal life and retreat into a torpid or dormant state. Organisms "wait out" the stress using a slow catabolism of stored fuels to maintain a minimum metabolic rate until conditions are again permissive for renewed activity, growth, and development. For example, painted turtles submerged in cold water show an anoxia-induced metabolic rate depression of about $90 \%$ compared with the rate in air at the same temperature. ${ }^{3}$ Hypometabolism underlies many survival strategies including anaerobiosis (living without oxygen), anhydrobiosis (life in a dry state), diapause (arrested development), freeze tolerance (survival with 50\%-70\% of body water frozen as extracellular ice), estivation (aerobic dormancy triggered by water or nutrient challenge, often in hot climates), and mammalian hibernation (prolonged cold torpor in response to the thermal and nutrient challenges of winter). ${ }^{4-11}$ Net metabolic rate suppression in hypometabolic states is typically $>80 \%$ and often $95 \%$ or more compared with resting metabolism in the active state. In some cryptobiotic systems, virtually no metabolic activity can be detected. ${ }^{7,9}$ Entry into hypometabolism can be seasonal (eg, winter hibernation) or linked with a life stage (eg, obligate diapause at one stage of development) or an opportunistic event, occurring whenever environmental conditions are poor (eg, anaerobiosis whenever oxygen availability fails).

\section{Molecular mechanisms of hypometabolism}

All of these forms of hypometabolism have been well studied as independent phenomena but, in recent years, work by my laboratory and others has shown that they all share commonalities of their biochemistry that address two main requirements: a) the metabolic regulation needed to control transitions to/from the hypometabolic state, and b) cell preservation strategies needed to sustain viability over long-term dormancy. ${ }^{9,10,12}$

Metabolic regulatory mechanisms orchestrate a strong net suppression of energy (ATP) turnover by the organism and do so in a way that preserves the core functions needed for viability. Both ATP-utilizing and ATP-generating cell functions are targeted for suppression and a priority system is used so that functions that are critical to viability (eg, maintaining membrane potential difference) are preferentially sustained whereas many 'optional' cell functions (eg, protein synthesis, cell proliferation, growth) are largely shut down..$^{9-12}$
For example, to continue with the turtle model, studies of anoxia effects on isolated turtle hepatocytes showed a net 94\% decrease in ATP turnover and a prominent redistribution of ATP use, compared with aerobic conditions. ${ }^{13}$ Membrane $\mathrm{Na}^{+} \mathrm{K}^{+}$ATPase became the primary consumer of ATP in anoxic cells, using about two-thirds of total ATP turnover compared with only about one-quarter in normoxia, whereas ATP use for protein synthesis and degradation was reduced by $>90 \%$. Indeed, global suppression of gene transcription, protein translation, and proteolysis are now known to occur in all forms of natural hypometabolism. ${ }^{10-12}$ For example, during estivation by land snails (Otala lactea), the rate of ${ }^{3} \mathrm{H}$-leucine incorporation into new proteins in hepatopancreas was reduced by $80 \%-90 \%$ compared with the rate in active snails, whereas activity of the $20 \mathrm{~S}$ proteasome (a measure of protein degradation) fell by $70 \%-75 \%$ (Figure 1 ). ${ }^{14}$

The primary mechanism that regulates and coordinates the suppression of multiple metabolic enzymes and functional proteins when animals enter hypometabolism is covalent modification of proteins via reversible phosphorylation. Known targets include ion motive ATPases, ribosomal initiation and elongation factors (eg, eIF2 $\alpha$, eEF-2), transcription factors, and multiple enzymes of anabolic and catabolic pathways in intermediary metabolism. ${ }^{9-12}$ Many studies have documented reduced activities and altered properties of a wide range of enzymes and functional proteins in hypometabolic states as well as identified the protein kinases and protein phosphatases that mediate these processes. For example, Figure 1B shows that during estivation, two key ribosomal proteins that regulate protein synthesis are strongly inhibited in $O$. lactea hepatopancreas. The amount of phosphorylated (Ser51) inactive eukaryotic initiation factor 2 alpha subunit (eIF2 $\alpha$ ) increased by 3.8- and 16-fold after 2 and 14 days of estivation, respectively, whereas phosphorylated (Thr56) eukaryotic elongation factor 2 (eEF2) content increased by $\sim 10.5$-fold. ${ }^{14}$

Cell preservation strategies are also key to long-term survival because organisms in dormant or torpid states are typically unable to alter their food/water status, move to ameliorate changes in environmental parameters (eg, temperature, oxygen, radiation), and have limited capacities to deal with stress by ATP-expensive macromolecular restructuring. Hence, most natural states of hypometabolism are supported by the prior accumulation and storage of large reserves of fuels, carbohydrates for oxygen-limited situations (eg, anaerobiosis, freeze tolerance) or lipids for aerobic situations (eg, estivation, hibernation), often accumulated on a seasonal or developmental pattern. In some cases, these fuels also support specialized 
A

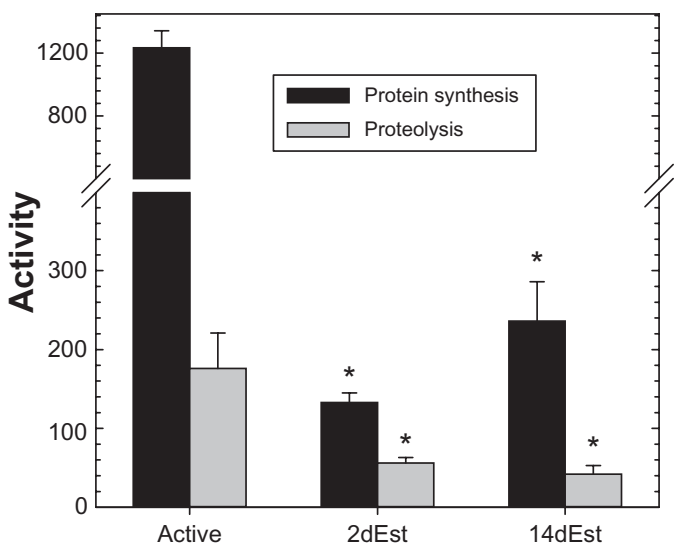

B

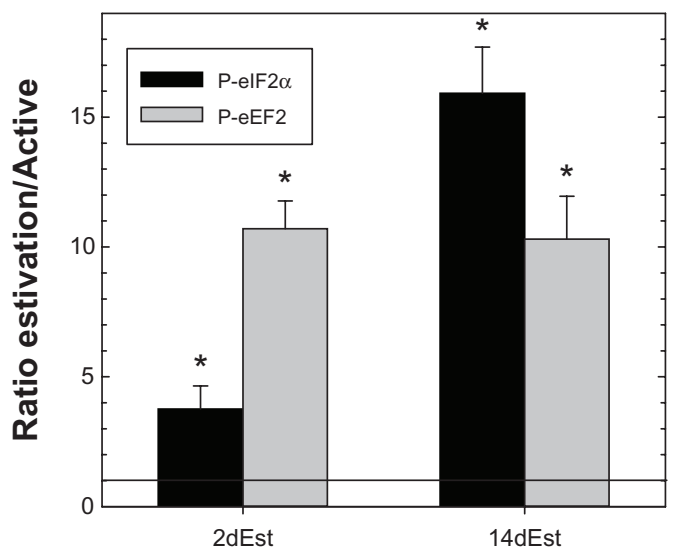

Otala lactea hepatopancreas

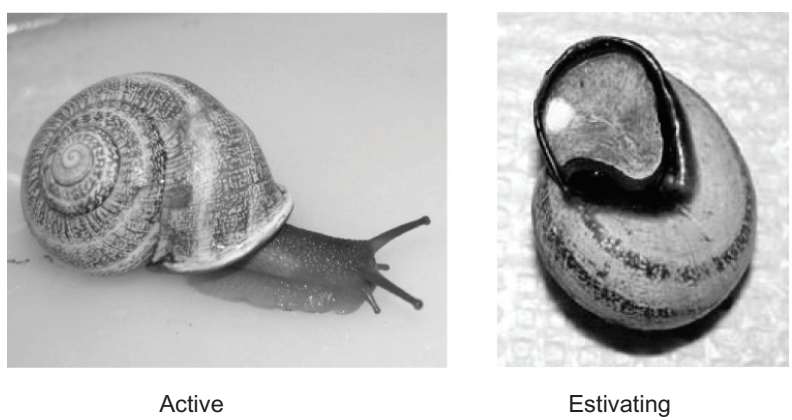

C

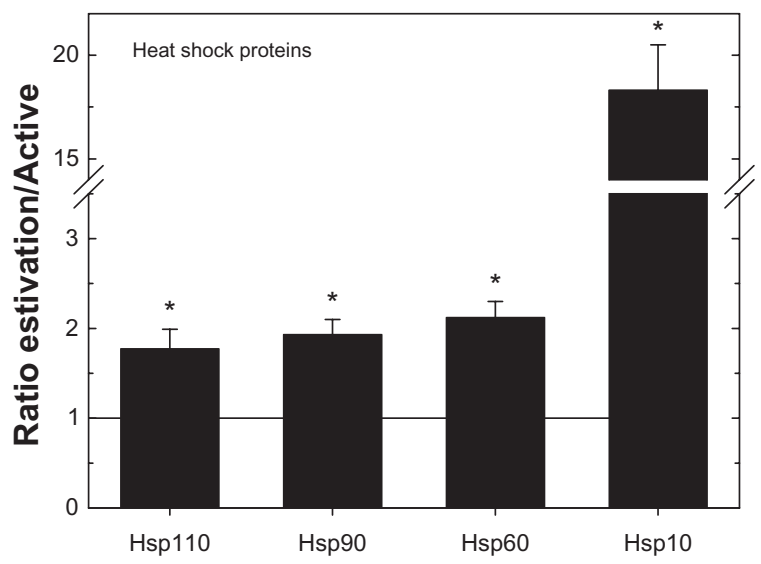

Figure I Biochemical parameters of metabolic rate depression in hepatopancreas of estivating land snails, Otala lactea. A) Rates of protein synthesis (measured as [ $\left.{ }^{3} \mathrm{H}\right]$-leucine incorporation into acid-precipitable protein) and activity of the 20S proteosome (measured with Z-LLE peptide as the substrate) in active (control), 2-day and I4-day estivating (Est) snails. B) Ratio of the amount of phosphorylated inactive ribosomal proteins, elF2 $\alpha$ (Ser5I), and eEF2 (Thr56) (analyzed by immunoblotting) in estivating versus active snails. C) Relative levels of $\mathrm{Hspl} 10, \mathrm{Hsp} 90, \mathrm{Hsp} 60$, Hspl 0 in hepatopancreas of I4-day estivated versus active snails (analyzed by immunoblotting).

Notes: Data are means \pm SEM, $n=4-5$ animals, except $n=6-8$ for proteosome activity. *Significantly different from the corresponding active value as determined by the Student's $t$-test, $P<0.05$.

Compiled from Ramnanan et al. ${ }^{14}$ Photographs by JM Storey.

synthesis of low-molecular-weight osmolytes that aid water retention and protect macromolecules. For example, estivating amphibians accumulate urea to provide colligative resistance to evaporative water loss, ${ }^{15}$ whereas cold-hardy insects synthesize huge amounts of polyhydric alcohols (comprising as much as $20 \%$ of body mass) to provide cryoprotection at sub-zero temperatures. ${ }^{16}$ Cold-hardy species also invest in highly specialized proteins that help them to either avoid freezing (eg, antifreeze proteins) or manage ice accumulation (ice-nucleating proteins). ${ }^{17}$

Given that global suppression of gene transcription, protein synthesis, and protein degradation are all known energy-saving features of hypometabolism, the preservation of the existing proteome becomes key to long-term survival during dormancy. ${ }^{10}$ For instance, an extreme example is a reported 77 -fold increase in the half-life of cytochrome oxidase in encysted gastrulae of the brine shrimp Artemia franciscana. ${ }^{18}$ One mechanism that has received much recent attention as a means of stabilizing a functional proteome is antioxidant defense. All forms of hypometabolism examined to date show enhanced enzymatic antioxidant defenses occurring either as a) higher constitutive defenses compared with stress intolerant species, or b) stress-induced upregulation of defenses. ${ }^{19,20}$ Antioxidants are best known for their action in destroying reactive oxygen species (ROS) before they can damage macromolecules but they are also involved in the repair or destruction of damaged macromolecules. ${ }^{21}$ Their importance to hypometabolism can include both protection of macromolecules over extended periods of dormancy (when rates of turnover of macromolecules are suppressed) as well as dealing with the challenge of "spikes" of ROS formation that accompany the rapid increase in oxygen consumption when animals exit the hypometabolic state. 
Another mechanism that could contribute to protecting the proteome during hypometabolism is the action of chaperone proteins. Chaperones help to fold or refold other proteins to ensure that cellular proteins attain or retain their functional conformation. ${ }^{22}$ The best known of these are the heat shock proteins (HSPs) that were so named due to their discovery as a response to high temperature stress. HSPs are now recognized as having very well-known roles in organismal responses to stresses of many kinds. However, what the present article demonstrates is that enhancement of HSPs is also an integral part of natural hypometabolism, providing a preparatory or anticipatory adjustment that sets up an organism with enhanced stress tolerance that remains in place throughout a period of environmentally induced dormancy. That is, enhanced expression of HSPs in hypometabolic systems is a proactive response to upcoming life history events (eg, dry season estivation, prolonged submergence, winter cold) as opposed to their better known reactive response that occurs only when stress conditions have begun to play havoc with cellular metabolism. The remainder of this review summarizes available information about HSPs and their role in cytoprotection during hypometabolism.

\section{HSPs and the stress response}

Unique changes in the puffing pattern of polytene chromosomes in the salivary glands of larval Drosophila melanogaster were first reported as a response to heat shock in $1962^{23}$ and it was later determined that this gene activity caused a massive expression of so-called HSPs. ${ }^{24}$ In subsequent years the function of HSPs as molecular chaperones was elucidated. They prevent the aggregation of unfolded proteins (either newly synthesized or denatured), facilitate folding of immature proteins or refolding of malfolded proteins, and aid in intracellular protein trafficking and assembly. ${ }^{22,25,26} \mathrm{HSPs}$ are now known to be a universal organismal response to many kinds of stresses that can damage the proteome. Indeed, HSPs are an important and integral component of the minimal stress proteome of cells. ${ }^{27}$ This is a conserved set of cell functions that addresses, for example, cell cycle control, protein chaperoning and repair, DNA and chromatin stabilization and repair, and removal of damaged proteins. Classically, the heat shock response is triggered by a high-temperature-induced protein unfolding crisis that, when temperature cools again, causes a shutdown of most normal protein syntheses and initiates instead a massive synthesis of chaperones that attempts to rescue cell proteins by refolding them into their functional conformations. ${ }^{22}$ More recently, it is becoming clear that HSPs (and other elements of the stress response) also play roles in longevity and life extension..$^{27,28}$ What has not been fully appreciated previously is the concept that HSPs also contribute to preparatory programs that set up organisms for long-term survival in hypometabolic states. This latter concept is the focus of the present review.

HSPs fall into several major families based on their molecular masses, including Hsp100, Hsp90, Hsp70, Hsp60, Hsp40, and small HSPs (sHsps) (less than $30 \mathrm{kDa}$ ) families. ${ }^{25,26}$ It should be noted that a revised nomenclature that does not use a molecular mass designation has recently begun to be used in the mammalian literature and calls these families HSPH, HSPC, HSPA, HSPD, DNAJ, and HSPB, respectively. ${ }^{29}$ However, none of the literature reviewed here uses these designations. The HSP families include both constitutively expressed and stress-inducible members. Functions are briefly summarized below. The Hsp70 family is the best known, containing both constitutive (Hsc70) and inducible (Hsp70) members. These partner with Hsp110 and Hsp40 and have prominent roles in protein folding/refolding in cytoplasmic and nuclear compartments. Hsp70 family proteins conduct the actual ATP-dependent folding of proteins, the binding of ATP triggering a critical conformational change that leads to the release of the bound substrate protein. ${ }^{30}$ Hsp40 contributes to the overall reaction by stimulating ATPase activity and activating the substrate binding of Hsp 70 $0^{31}$, whereas Hsp110 catalyzes nucleotide exchange on Hsp 70..$^{32}$ Like Hsp70, Hsp90 conducts ATP-dependent folding of proteins but appears to be fairly selective in the types of proteins that it folds (eg, cell signaling components), has over a dozen co-chaperone proteins with which it interacts, and can also induce conformational changes in folded, native-like substrate proteins that lead to their activation or stabilization. ${ }^{33,34} \mathrm{Hsp} 60$ proteins are chaperones of the mitochondrial compartment where they partner with Hsp10 in the folding and assembly of proteins that are transported into these organelles..$^{35}$ The small HSP family contains a variety of members with various actions including the $\alpha$ - and $\beta$-crystallins; for example, $\alpha \mathrm{A}$ and $\alpha \mathrm{B}$ crystallin are highly effective in preventing the depolymerization of actin in the cytoskeleton. ${ }^{36}$ In addition to chaperone effects, some HSPs provide additional protective actions that would be valuable during hypometabolism. For example, Hsp27, Hsp70, and Hsp90 have been implicated in the inhibition of apoptosis; they can bind Apaf-1 (apoptosis protease activating factor-1) and inhibit events downstream of Apaf- 1 activation, such as the activation of caspases. ${ }^{37,38} \mathrm{Hsp} 27$ can suppress apoptosis by inhibiting the release of mitochondrial cytochromes and can also confer resistance to oxidative stress. ${ }^{39,40}$ 


\section{HSPs in estivation}

Estivation is defined as a dormancy that is generally triggered by arid conditions, often in hot climates and frequently on a seasonal basis. Metabolic studies of estivation have mainly centered on land snails, frogs/toads, and lungfish as primary models. ${ }^{11}$ Our studies of land snails, O. lactea, documented strong global suppression of both protein synthesis and protein degradation during estivation (Figure 1), ${ }^{14}$ and this means that the functional lifespan of cellular proteins must be extended during estivation by mechanisms that preserve/protect existing proteins. Recent work indicates that estivation-mediated enhancement of HSPs could contribute to this. Four HSPs were analyzed in $O$. lacte $a$ and levels of all were significantly higher in hepatopancreas from 14-day estivated snails as compared with active snails. Hsp10 levels rose by a huge 18.3-fold whereas Hsp110, Hsp90, and Hsp60 increased by 1.8- to 2.1 -fold (Figure 1C). ${ }^{14} \mathrm{Hsp} 10$ levels also increased by 10.8 -fold in the foot muscle of estivating snails,,${ }^{14}$ and Hsp70 was $2.2 \pm 0.23$ - and $2.7 \pm 0.34$-fold higher in the hepatopancreas and foot after 14 days estivation (M Allan and K Storey, unpublished). Interestingly, an early study using ${ }^{35} \mathrm{~S}$-methionine to label estivation-responsive proteins in $O$. lactea showed strong labeling of four main proteins in hepatopancreas with masses of $91,70,50$, and $30 \mathrm{kDa}^{41}$ Based our current knowledge of HSP expression, it is probable that at least Hsp90 and Hsp70 were represented among these ${ }^{35} \mathrm{~S}$-labeled proteins. However, in contrast to the results for $O$. lactea, no significant change in Hsp70 transcript or protein expression was reported in another snail, Cantareus apertus, during estivation. ${ }^{42}$

New studies of two congeneric land snails, the desiccation-resistant desert Sphincterochila zonata and the desiccation-sensitive $S$. cariosa, add further insights into the roles of HSPs during estivation. Hsp 90, Hsp72, and Hsp74 were all up-regulated during experimental desiccation but their expression responded earlier in $S$. cariosa than in S. zonata ${ }^{43}$ By contrast, small HSPs (Hsp25, Hsp30) were more strongly expressed in $S$. zonata. The authors suggested that in the development of desiccation resistance, the desertadapted species (S. zonata) moved away from a reliance on Hsp70/Hsp90 expression and towards a more specialized response by the small HSPs. However, the data for these two congeners could also indicate a higher threshold for water loss by $S$. zonata before cytoprotective responses are triggered. Arousal from estivation further elevated HSPs in tissues (except for Hsp90 in the foot) indicating a need for chaperone action in rescuing protein function during arousal. ${ }^{44}$

\section{HSPs in hibernation}

Hibernation is the key to winter survival for many small mammals. By sinking into cycles of deep cold torpor, many species elude two key problems posed by winter: lack of food and cold ambient temperatures that place enormous demands on thermogenesis if animals aim to maintain a $37^{\circ} \mathrm{C}$ body temperature. However, by "unhooking" the hypothalamic thermostat, allowing body temperature to sink to near-ambient (often as low as $0-5^{\circ} \mathrm{C}$ ) and applying strong metabolic suppression, hibernators often reduce metabolic rate by 95\%-99\% compared with euthermia. ${ }^{45}$ Against a background of strong global suppression of transcription and translation, selected genes/proteins are upregulated during hibernation and several studies have shown that HSPs are among these. Admittedly, however, there is still no clear consensus about HSP involvement in hibernation due to several factors, including: a) application of different methods to screen for gene or protein expression, $b$ ) tissue and species differences in responses, and c) type of experimental comparison, ie, some studies compare summer versus winter animals whereas other analyze changes over a torpor-arousal cycle.

Available information to date includes the following. Seasonal enhancement of Hsp70 was documented during a study of atrophy resistance in hibernating bats (Murina leucogaster); 1.7-fold higher expression levels of Hsp70 were reported in the muscle of winter bats (hibernating or aroused) compared with summer-active animals. ${ }^{46}$ In another bat (Myotis lucifugus), both total Hsp27 protein and the amount of phosphorylated Hsp27 were 4.4- and 2.2-fold higher, respectively, in the hearts of torpid versus aroused animals. ${ }^{47} \mathrm{Hsp} 27$ is an ATP-independent chaperone that has a wide range of roles including the inhibition of protein aggregation under stress conditions (especially heat), protection of actin filaments, inhibition of apoptosis, activation of the $26 \mathrm{~S}$ proteasome, and stimulation of glutathione levels to enhance antioxidant defense by an Hsp27-mediated upregulation of glutathione-related enzymes. ${ }^{40,48}$ Resistance to oxidative stress is of particular importance for hibernators both to support long-term torpor (when capacity for protein turnover is very low) and especially during arousal when ROS generation soars in parallel with the massive increase in oxygen consumption that is needed to rewarm the body. In thirteen-lined ground squirrels (Spermophilus tridecemlineatus), Hsp70 in the intestine varied over torpor bouts, being highest during entrance and early hibernation and decreasing by about $50 \%$ during arousal and interbout periods. ${ }^{49} \mathrm{~A}$ proteomics approach also showed elevation of an Hsp70 family member (HSPA5 or Grp78) and Hsp90B1 in 
the liver of $S$. tridecemlineatus entering torpor compared with summer-active animals. ${ }^{50}$ Several gene screening studies also reported enhanced $h s p$ gene expression during cold torpor in ground squirrels. Transcript levels of hsp40, hsp60, and $h s p 70$ were identified as putatively upregulated during cold torpor (compared with euthermic controls) in the liver of S. tridecemlineatus. ${ }^{51}$ Gene screening of brown adipose tissue (BAT) from arctic ground squirrels (Spermophilus parryii) found overexpression of selected $h s p 70$ and $h s p 40$ forms in winter torpid animals compared with summer-active squirrels. ${ }^{52}$ A multi-tissue comparison of summer, winter torpid, and winter-aroused animals also revealed selective changes in Hsp90abl and Hspe1. ${ }^{53}$ Among other results, Hsp90ab1 was overexpressed in the liver and muscle during arousal. Mammalian hibernation is a complex phenomenon that involves not just hypometabolism but major changes in body temperature (often more than $30^{\circ} \mathrm{C}$ ), and much work remains to be done to thoroughly understand the ways in which HSPs contribute to hibernation. These could include, among others: a) stabilization of the proteome over days or weeks during each bout of cold torpor, b) addressing protein refolding requirements resulting from conformational changes caused by large changes in body temperature during entry into and arousal from torpor, and c) folding new proteins that are made to replace damaged proteins during the brief periods of interbout arousal.

\section{HSPs in anaerobiosis}

By its very nature, anoxia places energy stress on the cells of organisms that normally depend on oxygen-based metabolism because of the much lower ATP yield from glucose catabolism to lactate compared with full oxidation to $\mathrm{CO}_{2}$ and $\mathrm{H}_{2} \mathrm{O}$. Anoxia-tolerant organisms use strong metabolic rate depression to greatly reduce their ATP demands when oxygen is absent, but energy cutbacks to biosynthetic functions such as protein synthesis mean that a greater emphasis must be placed on the preservation of macromolecules to ensure viability over unpredictable lengths of anaerobiosis. A role for HSPs in anaerobiosis is supported from studies with the best vertebrate facultative anaerobes: turtles and carp.

Several studies have reported elevated HSPs in tissues of anoxia-tolerant turtles. Constitutive levels of mitochondrial Hsp60 were higher in the heart of anoxia-tolerant painted turtles compared with anoxia-intolerant softshell turtles, rabbits, and rats. ${ }^{54}$ High constitutive levels of inducible Hsp70 also occur in turtle brain ${ }^{55}$ although this protein is typically thought of as being absent or in very low levels in unstressed organisms. High constitutive expression of HSPs could provide turtle organs with a well-developed innate level of protection against protein denaturation that can be called into play whenever anoxia exposure occurs. Given the diving lifestyle of painted turtles, hypoxia/anoxia excursions are a frequent and unpredictable part of normal life. Hence, as has also been argued for the constitutively high antioxidant defenses of turtle organs, ${ }^{20}$ high constitutive expression of chaperone proteins would provide a consistent level of preparedness for anoxia survival.

HSPs are also inducible in response to anoxia in turtles, including Hsp25/27, Hsp40, Hsp60, Hsp70, Hsc70, and Hsp90. ${ }^{55-58}$ Figure 2 summarizes HSP responses to 20 hours of anoxic submergence and 5 hours of aerobic recovery in the white muscle of red-eared slider turtles (Trachemys scripta elegans). Anoxia induced a strong 2- to 3-fold increase in protein levels of Hsp25, Hsp40, Hsp70, Hsc70, and Hsp90 in muscle. ${ }^{58}$ Furthermore, levels of Hsp70 and Hsp90 remained elevated by 1.8 - to 2.9 -fold over controls after 5 hours of aerobic recovery. HSPs were also upregulated by 1.5- to 2.5-fold during anoxia in the liver (Hsp40, Hsp60, Hsp70, Hsc70) and kidney (Hsp40, Hsc70) along with a remarkable 6-fold increase in Hsp90 in kidney. ${ }^{58}$ As in muscle, HSPs in these organs generally returned to near control levels after 5 hours of aerobic recovery showing that HSP expression is a dynamic response to anoxia that functions to stabilize the cellular proteome whenever turtles transition into anoxic hypometabolism. DNA array screening for anoxia-responsive genes in turtle brain also found several $h s p$ genes ( $h s p 70, h s p 40, \alpha B$-crystallin) that were upregulated. ${ }^{59}$ This is supported by the observed activation of the heat shock transcription factor (HSF1) in turtle tissues under anoxia. ${ }^{58}$ For example, white skeletal muscle showed a 5-fold increase in the amount of active phosphorylated HSF1 under anoxia as well as an $80 \%$ increase in nuclear localization.

The timing of HSP production during anoxia exposure is also intriguing. Hsp70, Hsc70, and Hsp90 were unaffected over the early hours of a forced dive in painted turtles tissues but generally rose 2- to 3-fold after 12-30 hours, indicating that chaperones become more important when anoxia exposure is prolonged. ${ }^{56}$ It is well known that turtle diving has a two-phase pattern. Initially, animals go through a hypoxia transition period during which metabolic rate stays near normal until blood oxygen falls to a critical minimum $\mathrm{pO}_{2}$. Below this value, metabolic suppression is triggered and animals instigate all of the long-term anoxia survival strategies that are needed..$^{60}$ Therefore, this pattern of HSP upregulation supports the idea that enhancement of HSP levels is linked with the actual entry into hypometabolism. 


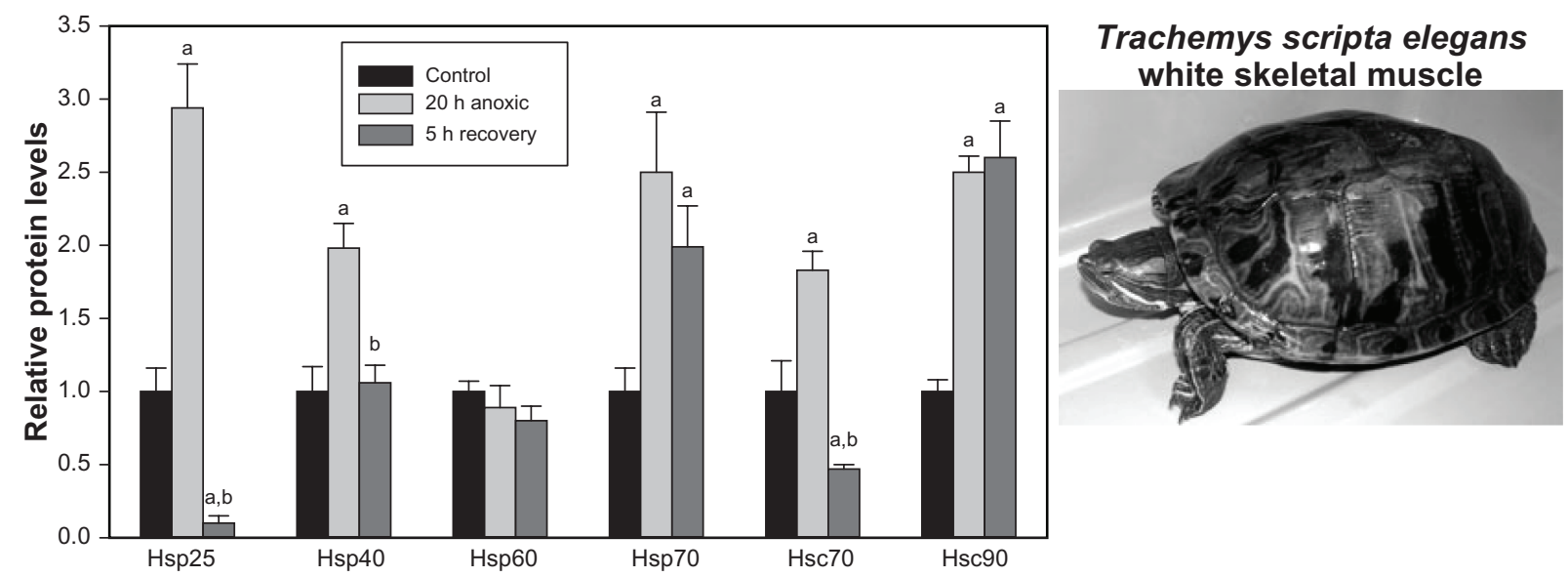

Figure 2 Effect of 20 hours of anoxic submergence and 5 hours of aerobic recovery on the protein levels of six heat shock proteins in the white skeletal muscle of red-eared slider turtles, Trachemys scripta elegans.

Notes: Histogram shows normalized protein levels, means \pm SEM, $n=4$ independent trials. aSignificantly different from the corresponding control, $P<0.05$; ${ }^{b}$ significantly different from the corresponding anoxic value, $P<0.05$.

Compiled from Krivoruchko and Storey. ${ }^{58}$ Photograph by JM Storey.

Anoxia-induced upregulation of $h s p$ gene expression was also reported recently for crucian carp (Carassius carassius), the best facultative anaerobe among fish. ${ }^{61}$ Anoxia tolerance allows carp to survive in ice-locked small ponds that become oxygen-depleted over the winter months. A unique metabolic strategy aids their survival; carp avoid metabolic poisoning by lactic acidosis by catabolizing lactate to ethanol and $\mathrm{CO}_{2}$ that are both excreted. ${ }^{62}$ Changes in transcript levels of five HSP genes were assessed in fish acclimated to $8^{\circ} \mathrm{C}$ and $13^{\circ} \mathrm{C}$. Expression of all genes showed anoxia-induced changes varying in size and direction, as well as with organ and temperature.$^{61}$ For example, $h s p 70 a$ transcripts increased $\sim 10$-fold in the brain and heart after 7 hours of anoxia at $13^{\circ} \mathrm{C}$ whereas hsc70 increased after 1 hour of anoxia in both organs at both temperatures. Of particular interest, normoxic fish showed 7- and 11-fold higher expression of hsp 70a in both organs in cold $\left(8^{\circ} \mathrm{C}\right)$ compared with warm $\left(13^{\circ} \mathrm{C}\right)$ water. Similarly, a decrease in normoxic temperatures from $26^{\circ} \mathrm{C}$ to $8^{\circ} \mathrm{C}$ caused a marked increase in protein levels of Hsp70/Hsc70 and Hsp90 in carp tissues. ${ }^{63}$ Overall, this suggests that low temperatures induce higher constitutive expression of selected HSPs and that this may be a component of cold-hardening that enhances hypoxia/anoxia tolerance in advance of predictable long-term low oxygen exposure during the winter.

\section{HSPs in insect diapause and cold-hardiness}

Diapause is a hypometabolic state that is characterized by developmental arrest. Entry into diapause is most often a survival strategy that allows a particular life stage to endure a period of environmental difficulty including water limitation, summer heat or winter cold. ${ }^{6}$ For example, the goldenrod gall fly (Eurosta solidaginis) enters diapause as a third-instar larva, the life stage that overwinters. Many insect species use specialized cold-hardiness strategies to survive sub-zero temperatures during the winter. ${ }^{16,17}$ Freeze-avoiding species orchestrate deep supercooling of their body fluids via accumulation of huge amounts of polyhydric alcohols combined with proliferation of antifreeze proteins. Freeze-tolerant species endure ice accumulation in extracellular spaces (often regulated by ice-nucleating proteins) coupled with high polyol concentrations that protect dehydrated intracellular spaces. ${ }^{16}$ Many cold-hardy insects are also in diapause for most of the winter.

The upregulation of HSPs is a component of diapause in a variety of insect species ${ }^{64,65}$ and is also known in other groups such as the embryonic diapause of killifish (Austrofundulus limnaeus).$^{66}$ Among insects, mRNA transcript levels of hsp 23 and $h s p 70$ were upregulated throughout pupal diapause in the flesh fly (Sarcophaga crassipalpis) although hsp 90 was suppressed. ${ }^{67}$ Further studies showed that transcript levels of both $h s p 70 a$ and $h s p 70 b$, one $h s p 60$ member and four small hsps were upregulated in diapausing $S$. crassipalpis. ${ }^{64} \mathrm{Hsp} 70$ was also upregulated in five other diapausing species $^{64}$ and $h s p 70 a$ transcripts also rose over time in diapause eggs of the silkworm (Bombyx mori). ${ }^{68}$

It is frequently hard to separate HSP expression as an adaptation supporting diapause as opposed to an adaptation preparing animals for cold-hardiness while in diapause. The two phenomena are closely linked and, in some cases, it is probable that upregulation of hsps is coincident with diapause entry in the autumn but may actually function as a 
preparation for cold survival. Several scenarios have been described. In the onion maggot, (Delia antiqua), hsp 70 transcript levels rose during both summer and winter diapauses showing a clear link with hypometabolism but cold stress also increased $h s p 70$ expression in both summer and winter diapausing pupae, showing the additional link to cold-hardiness ${ }^{69} \mathrm{Hsp} 70 \mathrm{a}$ transcripts rose in diapause eggs and to a lesser extent in nondiapause eggs of $B$. mori when transferred to $5^{\circ} \mathrm{C}$ but transcript levels dropped quickly when diapause eggs were transferred back to $25^{\circ} \mathrm{C}$, again implicating the need for HSPs as a part of cold tolerance. ${ }^{68}$ Hsp90 was upregulated during cold acclimation in nondiapausing larvae of the rice stem borer, (Chilo suppressalis), but not in diapausing larvae that had already elevated levels of the chaperone. ${ }^{70}$ Other evidence of the link between HSPs and cold-hardiness comes from an analysis of larvae of the Antarctica flightless midge, (Belgica antarctica), that showed constitutive upregulation (not further enhanced by heat or cold exposure) of transcript levels of $h s p 70, h s p 90$, and a small $h s p$ over the 2-year life of the larvae. This could equip the larvae with continual preparedness for dealing with both thermal and freeze/thaw stresses. ${ }^{71}$ By contrast, the short-lived adults that emerge only in summer do not show this feature but display the more usual pattern of thermal activation of HSPs.

New studies have also shown that HSPs contribute to the winter survival of two species of goldenrod gall forming insects. Gall moth larvae, (Epiblema scudderiana), use the freeze avoidance strategy and can supercool to $-38^{\circ} \mathrm{C} .{ }^{72}$ Analysis of Hsp110, Hsp70, Hsp60, and Hsp40 showed that protein levels of all four were significantly increased by 2 - to 2.5-fold in the larvae during the midwinter months compared with September values. ${ }^{73}$ Freeze-tolerant E. solidaginis larvae, showed a similar response (Figure 3). Protein levels of Hsp110, Hsp70, and Hsp40 (recall that these three work together) all rose over the late autumn and winter in the larvae, reaching 1.5 - to 2.0 -fold higher than September values. ${ }^{74}$ Interestingly, levels of the mitochondrial Hsp60 decreased by about $50 \%$ during the winter in E. solidaginis. This correlates with comparable reductions in mitochondrial DNA content and activities of mitochondrial enzymes in this freeze-tolerant species that indicate winter degradation of these organelles. ${ }^{75}$ By contrast, the freeze-avoiding species, E. scudderiana, does not show mitochondrial degradation in winter. The months of October through March are those when the larvae of both species exhibit cold-hardiness with high levels of cryoprotectants. ${ }^{72}$ However, the period of diapause is a more restricted 3-3.5 months; for example, in E. solidaginis this begins in late October and following diapause, larvae enter a period of cold quiescence until warming temperatures in the spring initiate pupation. Hence, high HSPs correlate with the full season of cold-hardiness and not just the shorter diapause period. This suggests a targeted benefit of chaperones for cold-hardiness. The same conclusion was drawn from the study of pupal diapause in $S$. crassipalpis. Transcript levels of $h s p 70$ and $h s p 23$ genes were upregulated when diapause began, but with the use of RNAi knockdown, it was shown that expression of these genes did not affect diapause capacity but reduced cold-tolerance during diapause. ${ }^{64}$

Elevated HSPs over the winter could contribute in a number of ways to cell preservation for cold-hardy insects. For freeze-tolerant species, freezing of extracellular body fluids sets up anoxic and ischemic conditions and, as described earlier for anoxia-tolerant animals, chaperone action would contribute to protein preservation under the energy-restricted conditions of the frozen state. Furthermore, all proteins are sensitive to temperature change with both heat and cold denaturation described in numerous cases. Given that winter temperatures for many species could vary from above $0^{\circ} \mathrm{C}$ to $-50^{\circ} \mathrm{C}$ or lower, constitutive chaperone defenses could also be necessary in order to stabilize protein conformations over wide ranges in environmental temperatures as well as freeze/thaw cycles. For example, cold shock can cause actin disassembly and recent studies have shown a critical role for a chaperone called CCT (chaperonin containing t-complex polypeptide-1) in stabilizing actin in vivo at low temperatures in D. antiqua. ${ }^{76}$ Nonhardy pupae showed cold-induced depolymerization of actin but cold-hardy pupae did not and this correlated with the coordinated upregulation of all CCT subunits in cold-hardy pupae. Finally, proteins in freeze-tolerant species could also be susceptible to freeze denaturation. Most freeze-tolerant animals endure freezing of $65 \%$ or more of total body water ${ }^{16}$ but this causes an approximate 3 -fold increase in concentrations of all dissolved molecules (eg, ions, metabolites, proteins) in remaining intracellular fluids. Such levels could promote denaturation and/or aggregation of proteins and enhanced amounts of chaperones could be important for preventing and/or reversing such problems over cycles of freezing and thawing.

\section{HSPs in anhydrobiosis}

Anhydrobiosis, also called cryptobiosis, is a truly extreme lifeform; virtually no metabolic activity can be detected because there is essentially no free water in which biochemical reactions can occur. Many kinds of microscopic organisms exhibit 


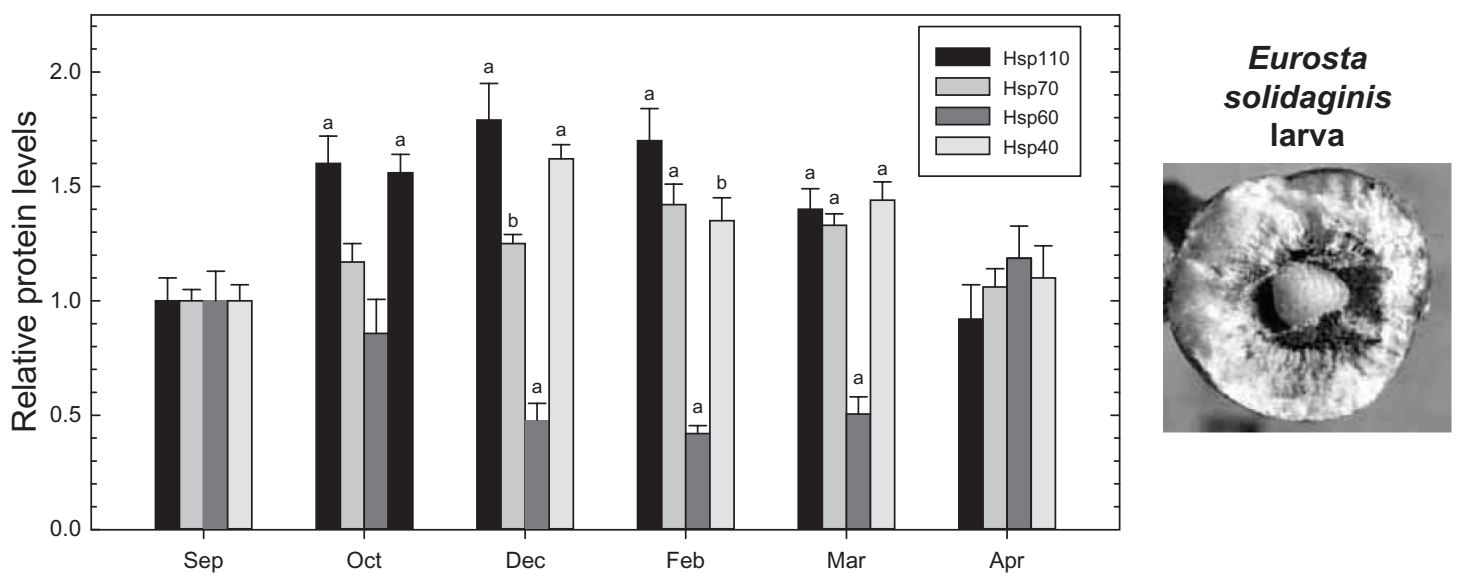

Figure 3 Expression of Hsp I 10, Hsp70, Hsp60, and Hsp40 from September to April in freeze-tolerant Eurosta solidaginis larvae.

Notes: Data are means $\pm S E M, n=4$. aSignificantly different from the corresponding September value as determined by analysis of variance followed by a two-tailed Dunnett's $t$-test, $P<0.01 ;{ }^{b} P<0.05$.

Reprinted with permission from Zhang et al. ${ }^{74}$ Photograph by JM Storey.

anhydrobiosis at selected life stages, brine shrimp (Artemia salina) being the best-studied model. ${ }^{7}$ Brine shrimp experience one of two developmental pathways, producing either larvae or encysted embryos (cysts), the latter showing extreme stress resistance. Indeed, encysted embryos even have the remarkable ability to tolerate anoxia for years while remaining fully hydrated. Probably the first direct example of shock protein involvement with hypometabolism was the discovery of p26 that is accumulated in huge amounts in encysted brine shrimp embryos. ${ }^{77,78}$ This protein belongs to the small heat shock/ $\alpha$-crystallin family and in response to cellular acidification under stress conditions, migrates to the nucleus where it seems to have a key action in transcriptional repression. ${ }^{79}$ An adaptive advantage of $\mathrm{p} 26$ action is that it does not require energy input (ATP, GTP) and this allows it to function despite the almost total absence of any metabolic activity in either anhydrobiotic or anoxic embryos. Recent work has found two more small chaperones that also enhance Artemia survival, ArHsp21 and ArHsp22. ${ }^{80,81}$ These proteins differ in some characteristics but both are restricted to diapause-destined embryos, form large oligomers, and have been shown to prevent stressinduced aggregation or denaturation of proteins in vitro. The ATP-dependent Hsp70 is also found in anoxic embryos but at very low levels and is probably inactive due to fleetingly low ATP levels in the encysted larvae. ${ }^{79}$ It has been suggested that Hsp70 is retained in order to break up aggregates of p26 when embryos exit dormancy and cellular metabolism needs to be reactivated.

Contrary to the specialized proteins of Artemia, the more common HSPs support anhydrobiosis in the African sleeping chironomid (Polypedilum vanderplanki) during the dry season. Analysis of an expressed sequence tag database found prominent upregulation of genes encoding HSPs, antioxidants, late embryogenesis abundant proteins (associated with desiccation resistance), proteins of trehalose metabolism (a membrane protectant), and various transporters over the course of 36 hours of dehydration. ${ }^{82}$ Transcripts of $h s p 40, h s p 60, h s p 70, h s p 82, h s p 90$, and two $\alpha$-crystallins were all upregulated. A co-induction of small HSPs and Hsp70 was also reported in resting eggs of the rotifer Brachionus plicatilis ${ }^{83}$, and it was suggested that small HSPs prevent desiccation-induced aggregation of proteins (perhaps similar to Artemia Hsp21 and Hsp22) whereas Hsp70 acts to refold proteins during rehydration, as also implied for Artemia. A further examination of six heat shock genes ( $h s p 90, h s p 70, h s c 70, h s p 60, h s p 20$, and $p 23)$ in $P$. vanderplanki larvae found that all were significantly upregulated by dehydration. ${ }^{84}$ Transcripts of the larger proteins peaked at 24-48 hours of desiccation, following an earlier upregulation of HSF1 within 8 hours. Transcripts of hsp70 and $h s p 60$ also showed a second peak of expression during rehydration. Transcripts of small HSPs differed in the timing, with $p 20$ rising early and $p 23$ later during dehydration; the authors suggested that a late accumulation of p23 may indicate a role in mediating glass-state formation in anhydrobiotic larvae. By contrast, only limited changes in hsp gene expression were associated with anhydrobiosis in a tardigrade species. ${ }^{85}$

\section{Conclusion}

HSPs were first identified as a rescue response to extreme stress that damaged the proteome of an organism. HSP members were subsequently shown to have integral roles in stabilizing the proteome of all cells including folding of new 
proteins, rescue of malfolded or unfolded proteins, control of protein aggregation, and guiding protein translocation to subcellular sites. Expression of HSPs also proved to be an adaptive response to stress by organisms that are stresstolerant. The present review extends our understanding of the wide-ranging roles of HSPs by showing that HSP expression is a conserved mechanism that contributes to cytoprotection when animals enter natural states of hypometabolism. By entering a hypometabolic state, organisms can survive conditions (eg, cold, oxygen deprivation, desiccation, lack of food) that would otherwise be stressful and/or lethal. The evidence presented here shows that HSP expression is conserved across many forms of hypometabolism including estivation, hibernation, anoxia tolerance, freeze tolerance, diapause, and anhydrobiosis. As has also been documented for antioxidant defenses, animals that use hypometabolism as a survival strategy show multiple strategies of HSP expression. Some show enhanced constitutive expression of HSPs; for example, Hsp70 is typically thought of as being produced only under stress conditions but it is constitutive in several systems discussed here. Preparatory (or anticipatory) upregulation of HSPs as part of a seasonal or life stage program is also common; this makes sense so that cytoprotective proteins are in place and extensive synthesis is not required under the ATP-restricted conditions of the hypometabolic state. HSP upregulation that is directly triggered during a hypometabolic excursion also occurs; this pattern suits organisms that cannot predict when episodes of metabolic rate depression will be needed. Elevated HSPs in the hypometabolic state undoubtedly contribute to cytoprotection and long-term survival during dormancy by protecting the proteome. This is critical for three reasons. First, a strong suppression of gene expression, protein synthesis, and protein degradation as an energy-saving mechanism during hypometabolism means that the scope for new protein synthesis and/or degradation of damaged proteins is low and, therefore, protection of the structure/ function of the existing proteome becomes critical. Second, elevated chaperone capacity provides a pre-existing defense against stresses that are imposed during the hypometabolic excursion; (eg, protection of proteins in freeze-tolerant species against cold and/or freeze denaturation of proteins over unpredictable depths, duration, or cycles of freezing). Third, arousal from hypometabolism is often rapid and stressful (eg, involving large changes in temperature, oxygen, ROS), and HSPs will have a key role in ensuring that the transition back to the aroused state occurs with minimal negative impact on the organism. Overall, the present review demonstrates that adequate HSP defenses are an important principle of natural hypometabolism in the animal kingdom.

\section{Acknowledgments}

Thanks to recent students in the Storey lab who have contributed data and ideas about heat shock protein involvement in various models of hypometabolism including G Zhang, A Krivoruchko, and M Allan. Supported by a discovery grant from the Natural Sciences and Engineering Research Council of Canada and the Canada Research Chairs program.

\section{Disclosure}

No conflicts of interest were declared in relation to this paper.

\section{References}

1. Storey KB. Functional metabolism: regulation and adaptation. Hoboken, NJ: Wiley-Liss; 2004.

2. Storey KB. Metabolic adaptations supporting anoxia tolerance in reptiles: recent advances. Comp Biochem Physiol B. 1996;113:23-35.

3. Jackson DC. Living without oxygen: lessons from the freshwater turtle. Comp Biochem Physiol A. 2000;125:299-315.

4. Hochachka PW, Guppy M. Metabolic Arrest and the Control of Biological Time. Cambridge, MA: Harvard University Press; 1987.

5. Hochachka PW, Lutz PL. Mechanism, origin and evolution of anoxia tolerance in animals. Comp Biochem Physiol B. 2001;130: 435-459.

6. Denlinger DL. Regulation of diapause. Annu Rev Entomol. 2002;47: 93-122.

7. Clegg JS. Cryptobiosis - a peculiar state of biological organization. Comp Biochem Physiol B. 2001;128:613-624.

8. Heldmaier G, Ortmann S, Elvert R. Natural hypometabolism during hibernation and daily torpor in mammals. Respir Physiol Neurobiol. 2004;141:317-329.

9. Storey KB, Storey JM. Facultative metabolic rate depression: molecular regulation and biochemical adaptation in anaerobiosis, hibernation, and estivation. Quart Rev Biol. 1990;65:145-174.

10. Storey KB, Storey JM. Metabolic rate depression in animals: transcriptional and translational controls. Biol Rev Camb Philos Soc. 2004;79: 207-233.

11. Storey KB, Storey JM. Metabolic regulation and gene expression during aestivation. In: Navas CA, Carvalho JE, editors. Aestivation: Molecular and Physiological Aspects. Heidelberg, Germany: Springer; 2010:25-45.

12. Storey KB, Storey JM. Putting life on 'pause' - molecular regulation of hypometabolism. J Exp Biol. 2007;210:1700-1714.

13. Hochachka PW, Buck LT, Doll CJ, Land SC. Unifying theory of hypoxia tolerance: molecular/metabolic defense and rescue mechanisms for surviving oxygen lack. Proc Natl Acad Sci U SA. 1996;93: 9493-9498.

14. Ramnanan CJ, Allan ME, Groom AG, Storey KB. Regulation of global protein translation and protein degradation in aerobic dormancy. Mol Cell Biochem. 2009;323:9-20.

15. Storey KB. Life in the slow lane: molecular mechanisms of estivation. Comp Biochem Physiol A. 2002;133:733-754.

16. Storey KB. Organic solutes in freezing tolerance. Comp Biochem Physiol A. 1997;117:319-326.

17. Denlinger DL, Lee RE, editors. Low Temperature Biology of Insects. Cambridge, UK: Cambridge University Press; 2010.

18. Anchordoguy TJ, Hand SC. Acute blockage of the ubiquitin-mediated proteolytic pathway during invertebrate quiescence. Am J Physiol. 1994; 267:R895-R900. 
19. Hermes-Lima M, Storey JM, Storey KB. Antioxidant defenses and metabolic depression. The hypothesis of preparation for oxidative stress in land snails. Comp Biochem Physiol B. 1998;120:437-448.

20. Hermes-Lima M, Zenteno-Savin T. Animal response to drastic changes in oxygen availability and physiological oxidative stress. Comp Biochem Physiol C. 2002;133:537-556.

21. Hermes-Lima M. Oxygen in biology and biochemistry: role of free radicals. In: Storey KB, editor. Functional Metabolism: Regulation and Adaptation. Hoboken, NJ: Wiley-Liss; 2004:319-368.

22. Winter J, Jakob U. Beyond transcription - new mechanisms for the regulation of molecular chaperones. Crit Rev Biochem Mol Biol. 2004; 39:297-317.

23. Ritossa FM. A new puffing pattern induced by heat shock and DNP in Drosophila. Experientia. 1962;18:571-573.

24. Tissieres A, Mitchell HK, Tracy UM. Protein synthesis in salivary glands of Drosophila melanogaster: relation to chromosome puffs. J Mol Biol. 1974;84:389-398.

25. Gething MJ, Sambrook J. Protein folding in the cell. Nature. 1992; 355:33-45.

26. Feder ME, Hofmann GE. Heat-shock proteins, molecular chaperones, and the stress response: evolutionary and ecological physiology. Ann Rev Physiol. 1999;6:243-282.

27. Kultz D. Molecular and evolutionary basis of the cellular stress response. Annu Rev Physiol. 2005;67:225-257.

28. Krivoruchko A, Storey KB. Forever young: mechanisms of anoxia tolerance in turtles and possible links to longevity. Oxid Med Cell Longevity. 2010;3(3):186-198.

29. Kampinga HH, Hageman J, Vos MJ, et al. Guidelines for the nomenclature of the human heat shock proteins. Cell Stress Chaperones. 2009; 14:105-111.

30. Fink AL. Chaperone-mediated protein folding. Physiol Rev. 1999;79: 425-449.

31. Suh WC, Lu CZ, Gross CA. Structural features required for the interaction of the Hsp70 molecular chaperone DnaK with its cochaperone DnaJ. J Biol Chem. 1999;274:30534-30539.

32. Dragovic Z, Broadley SA, Shomura Y, Bracher A, Hartl FU. Molecular chaperones of the Hsp110 family act as nucleotide exchange factors of Hsp70s. EMBO J. 2006;25:2519-2528.

33. Trepel J, Mollapour M, Giaccone G, Neckers L. Targeting the dynamic HSP90 complex in cancer. Nat Rev Cancer. 2010;10:537-549.

34. Wandinger SK, Richter K, Buchner J. The Hsp90 chaperone machinery. J Biol Chem. 2008;283:18473-18477.

35. Cheng MY, Hartl FU, Martin J, et al. Mitochondrial heat-shock protein hsp60 is essential for assembly of proteins imported into yeast mitochondria. Nature. 1989;337:620-625.

36. Wang K, Spector A. Alpha-crystallin stabilizes actin filaments and prevents cytochalasin-induced depolymerization in a phosphorylationdependent manner. Eur J Biochem. 1996;242:56-66.

37. Beere HM, Wolf BB, Cain K, et al. Heat-shock protein 70 inhibits apoptosis by preventing recruitment of procaspase- 9 to the Apaf-1 apoptosome. Nat Cell Biol. 2000;2:469-475.

38. Pandey P, Saleh A, Nakazawa A, et al. Negative regulation of cytochrome $c$-mediated oligomerization of Apaf-1 and activation of procaspase-9 by heat shock protein 90. EMBO J. 2000;19:4310-4322.

39. Gorman AM, Szegezdi E, Quigney DJ, Samali A. Hsp27 inhibits 6-hydroxydopamine induced cytochrome $c$ release and apoptosis in PC12 cells. Biochem Biophys Res Commun. 2005;327:801-810.

40. Mehlen P, Preville X, Chareyron P, Briolay J, Klemenz R, Arrigo AP. Constitutive expression of human hsp27, Drosophila hsp27, or human alpha B-crystallin confers resistance to TNF- and oxidative stressinduced cytotoxicity in stably transfected murine L929 fibroblasts. J Immunol. 1995;154:363-374.

41. Brooks SP, Storey KB. Evidence for aestivation specific proteins in Otala lactea. Mol Cell Biochem. 1995;143(1):15-20.

42. Reuner A, Brümmer F, Schill RO. Heat shock proteins (Hsp70) and water content in the estivating Mediterranean grunt snail (Cantareus apertus). Comp Biochem Physiol B. 2008;151:28-31.
43. Mizrahi T, Heller J, Goldenberg S, Arad Z. Heat shock proteins and resistance to desiccation in congeneric land snails. Cell Stress Chaperones. 2010;15:351-363.

44. Arad Z, Mizrahi T, Goldenberg S, Heller J. Natural annual cycle of heat shock protein expression in land snails: desert versus Mediterranean species of Sphincterochila. J Exp Biol. 2010;213:3487-3495.

45. Geiser F. Metabolic rate and body temperature reduction during hibernation and daily torpor. Annu Rev Physiol. 2004;66:239-274.

46. Lee K, Park JY, Yoo W, et al. Overcoming muscle atrophy in a hibernating mammal despite prolonged disuse in dormancy: proteomic and molecular assessment. J Cell Biochem. 2008;104:642-656.

47. Eddy SF, McNally JD, Storey KB. Up-regulation of a thioredoxin peroxidase-like protein, proliferation-associated gene, in hibernating bats. Arch Biochem Biophys. 2005;435:103-111.

48. Arrigo AP. The cellular "networking" of mammalian Hsp27 and its functions in the control of protein folding, redox state and apoptosis. Adv Exp Med Biol. 2007;594:14-26.

49. Carey HV, Andrews MT, Martin SL. Mammalian hibernation: cellular and molecular responses to depressed metabolism and low temperature. Physiol Rev. 2003;83:1153-1181.

50. Epperson LE, Rose JC, Carey HV, Martin SL. Seasonal proteomic changes reveal molecular adaptations to preserve and replenish liver proteins during ground squirrel hibernation. Am J Physiol. 2010;298: R329-R340.

51. Storey KB. Mammalian hibernation: transcriptional and translational controls. Adv Exp Med Biol. 2003;543:21-38.

52. Yan J, Burman A, Nichols C, et al. Detection of differential gene expression in brown adipose tissue of hibernating arctic ground squirrels with mouse microarrays. Physiol Genom. 2006;25:346-353.

53. Yan J, Barnes BM, Kohl F, Marr TG. Modulation of gene expression in hibernating arctic ground squirrels. Physiol Genom. 2008;32:170-181.

54. Chang J, Knowlton AA, Wasser JS. Expression of heat shock proteins in turtle and mammal hearts: relationship to anoxia tolerance. $\mathrm{Am} \mathrm{J}$ Physiol. 2000;278:R209-R214.

55. Prentice HM, Milton SL, Scheurle D, Lutz PL. The upregulation of cognate and inducible heat shock proteins in the anoxic turtle brain. J Cereb Blood Flow Metab.2004;24:826-828.

56. Ramaglia V, Buck LT. Time-dependent expression of heat shock proteins 70 and 90 in tissues of the anoxic western painted turtle. $J$ Exp Biol. 2004;207:3775-3784.

57. Kesaraju S, Schmidt-Kastner R, Prentice HM, Milton SL. Modulation of stress proteins and apoptotic regulators in the anoxia tolerant turtle brain. J Neurochem. 2009;109:1413-1426.

58. Krivoruchko A, Storey KB. Regulation of the heat shock response under anoxia in the turtle, Trachemys scripta elegans. J Comp Physiol B. 2010;180:403-414.

59. Storey KB. Anoxia tolerance in turtles: metabolic regulation and gene expression. Comp Biochem Physiol A. 2007;147:263-276.

60. Lutz PL, Storey KB. Adaptations to variations in oxygen tension by vertebrates and invertebrates. In: Dantzler WH, editor. Handbook of Physiology, Section 13: Comparative Physiology. Oxford, UK: Oxford University Press; 1997;2:1479-1522.

61. Stensløkken KO, Ellefsen S, Larsen HK, Vaage J, Nilsson GE. Expression of heat shock proteins in anoxic crucian carp (Carassius carassius): support for cold as a preparatory cue for anoxia. Am J Physiol. 2010;298: R1499-R1508.

62. Lutz PL, Nilsson GE. Contrasting strategies for anoxic brain survival - glycolysis up or down. J Exp Biol. 1997;200:411-419.

63. Rissanen E, Tranberg HK, Sollid J, Nilsson GE, Nikinmaa M. Temperature regulates hypoxia-inducible factor-1 (HIF-1) in a poikilothermic vertebrate, crucian carp (Carassius carassius). J Exp Biol. 2006;209:994-1003.

64. Rinehart JP, Li A, Yocum GD, Robich RM, Hayward SA, Denlinger DL. Up-regulation of heat shock proteins is essential for cold survival during insect diapause. Proc Natl Acad Sci U S A. 2007;104: $11130-11137$.

65. Clark MS, Worland MR. How insects survive the cold: molecular mechanisms - a review. J Comp Physiol B. 2008;178:917-933. 
66. Podrabsky JE, Somero GN. An inducible $70 \mathrm{kDa}$-class heat shock protein is constitutively expressed during early development and diapause in the annual killifish Austrofundulus limnaeus. Cell Stress Chaperones. 2007;12:199-204.

67. Hayward SA, Pavlides SC, Tammariello SP, Rinehart JP, Denlinger DL. Temporal expression patterns of diapause-associated genes in flesh fly pupae from the onset of diapause through post-diapause quiescence. J Insect Physiol. 2005;51:631-640.

68. Moribe Y, Oka K, Niimi T, Yamashita O, Yaginuma T. Expression of heat shock protein 70a mRNA in Bombyx mori diapause eggs. J Insect Physiol. 2010;56(9):1246-1252.

69. Chen B, Kayukawa T, Monteiro A, Ishikawa Y. Cloning and characterization of the HSP70 gene, and its expression in response to diapauses and thermal stress in the onion maggot, Delia antiqua. J Biochem Mol Biol. 2006;39:749-758.

70. Sonoda S, Fukumoto K, Izumi Y, Yoshida H, Tsumuki H. Cloning of heat shock protein genes (hsp90 and hsc70) and their expression during larval diapause and cold tolerance acquisition in the rice stem borer, Chilo suppressalis Walker. Arch Insect Biochem Physiol. 2006;63:36-47.

71. Rinehart JP, Hayward SA, Elnitsky MA, Sandro LH, Lee RE, Denlinger DL. Continuous up-regulation of heat shock proteins in larvae, but not adults, of a polar insect. Proc Natl Acad Sci USA. 2006; 103:14223-14227.

72. Storey KB. Biochemical adaptation for cold hardiness in insects. Phil Trans R Soc London B. 1990;326:635-654.

73. Storey JM, Storey KB. Insects in winter: cold case files. In: Lovegrove BG, McKechnie AE, editors. Hypometabolism in Animals: Hibernation, Torpor and Cryobiology. Pietermaritzburg, South Africa: University of KwaZulu-Natal; 2008:83-92.

74. Zhang G, Storey JM, Storey KB. Chaperone proteins and winter survival by a freeze tolerant insect. J Insect Physiol. 2011. DOI: 10.1016/j. jinsphys.2011.02.016.

75. Storey KB, Storey JM. Oxygen: stress and adaptation in cold hardy insects. In: Denlinger DL, Lee RE, editors. Low Temperature Biology of Insects. Cambridge, UK: Cambridge University Press; 2010:141-165.
76. Kayukawa T, Ishikawa Y. Chaperonin contributes to cold hardiness of the onion maggot Delia antiqua through repression of depolymerization of actin at low temperatures. PLoS One. 2009;4:e8277.

77. MacRae TH. Molecular chaperones, stress resistance and development in Artemia franciscana. Semin Cell Dev Biol. 2003;14:251-258.

78. Willsie JK, Clegg JS. Nuclear p26, a small heat shock/alpha-crystallin protein, and its relationship to stress resistance in Artemia franciscana embryos. J Exp Biol. 2001;204:2339-2350.

79. Clegg JS. Protein stability in Artemia embryos during prolonged anoxia. Biol Bull. 2007;212:74-81.

80. Qiu Z, Macrae TH. ArHsp21, a developmentally regulated small heat-shock protein synthesized in diapausing embryos of Artemia franciscana. Biochem J. 2008;411:605-611.

81. Qiu Z, MacRae TH. ArHsp22, a developmentally regulated small heat shock protein produced in diapause-destined Artemia embryos, is stress inducible in adults. FEBS J. 2008;275:3556-3566.

82. Cornette R, Kanamori Y, Watanabe M, et al. Identification of anhydrobiosis-related genes from an expressed sequence tag databased in the cryptobiotic midge Polypedilum vanderplanki (Diptera; Chironomidae). J Biol Chem. 2010;285:35889-35899.

83. Denekamp NY, Thorne MA, Clark MS, Kube M, Reinhardt R, Lubzens E. Discovering genes associated with dormancy in the monogonont rotifer Brachionus plicatilis. BMC Genomics. 2009;10:108.

84. Gusev O, Cornette R, Kikawada T, Okuda T. Expression of heat shock protein-coding genes associated with anhydrobiosis in an African chironomid Polypedilum vanderplanki. Cell Stress Chaperones. 2011; 16:81-90.

85. Reuner A, Hengherr S, Mali B, et al. Stress response in tardigrades: differential gene expression of molecular chaperones. Cell Stress Chaperones. 2010;15:423-430.
Research and Reports in Biology

\section{Publish your work in this journal}

Research and Reports in Biology is an international, peer-reviewed, open access journal publishing original research, reports, editorials, reviews and commentaries on all areas of biology including animal biology, biochemical biology, cell biology, ecological studies, evolutionary biology, molecular biology, plant science and botany. The

\section{Dovepress}

manuscript management system is completely online and includes a very quick and fair peer-review system. Visit http://www.dovepress. com/testimonials.php to read real quotes from published authors. 